Military Technical College

Kobry El-Kobbah,

Cairo, Egypt

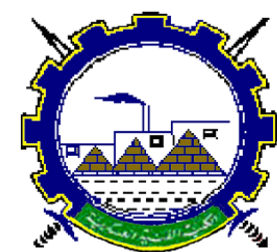

I.C.E.E.2016 $8^{\text {th }}$ International Conference

on

Chemical \& Environmental

Engineering

$19-21$ April 2016

\title{
CBP-4
}

\section{Chromatographic Determination of a Blistering Agent 2-Chloroethyl Ethyl Sulfide (CEES): Optimization of the Operating Conditions}

\author{
O.A.Zalat, M.A.Elsayed, M.K.Abd-elmegid,M.S.fayed \\ Egyptian Armed force
}

\begin{abstract}
This Paper discusses the determination of 2-chloroethyl ethyl sulfide (CEES), by gas chromatography equipped with flame photometric detector (GC-FPD) (S-mode). The analysis was performed on HP-5 MS, $30 \mathrm{~m} \times 0.32 \mathrm{~mm}$ capillary column with a $0.25 \mu \mathrm{m}$ stationary film thickness using ultra pure nitrogen $(99.9999 \%)$ as a carrier gas at 25 psi constant pressure. The method has been optimized. Factors affecting quantization of CEES such as injector temperature, carrier gas inlet pressure, air to hydrogen ratios and initial temperature program have been studied to get the best sensitivity, minimum delectability, dynamic range, linear range and noise. The linear ranges was $(0.15-10)$ ngSand limit of detection was $(0.15)$ $\mathrm{ng} / \mathrm{ml}$. The relative standard deviation (RSD \%) was $1.59 \%(\mathrm{n}=5)$, precision was over $99 \%$. The method is precise, reproducible and non linear over this range of concentration. It can be recommended as a suitable method for the quantification of (CEES).
\end{abstract}

Keywords: gas chromatography, GC-FPD (S-mode), analysis of CEES, sensitivity. 
Military Technical College

Kobry El-Kobbah,

Cairo, Egypt

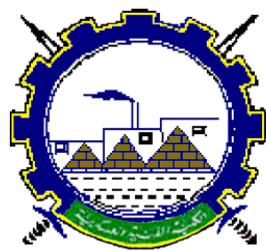

I.C.E.E.2016 $8^{\text {th }}$ International Conference

on

Chemical \& Environmental

Engineering

$19-21$ April 2016

\section{Introduction}

2-chloroethyl ethyl sulfide -CEES has a chemical structure similar to mustard gas except one chlorine atom [1].CEES and mustard gas have very similar crystal structures. Thus, it is expected that 2-CEES will closely like the reactivity of mustard gas [1]. Agilent technologies verify 2-CEES as a chemical warfare agent with symbol (T). CEES isknown to have immediate (minutes), long-term (hours to days) toxic effects on human skin [2]. CEES production and use as a stimulant for mustard and in studies involving decontamination, detection, contact hazards, and clothing protection may result in its release to the environment through various waste streams[3-6].

As a result, detection method should be capable of positive identification of these compounds. The analytical techniques of high sensitivity, selectivity and speed of analysis are needed for the analyses of these compounds. The most widely used technique for the analysis of CEES is capillary gas chromatography [7-9]. High-performance liquid chromatography has also been applied to successful identification $[8,10,11]$.

The chromatographic techniques permit for separating 2-CEES and their degradation products in the environmental samples. In general, a high-resolution gas chromatographic separation can require up to $30 \mathrm{~min}$ to complete separation and detection of a complex mixtures. However, when selective detectors are used in combination with GC, the separation time can be reduced significantly $[5,12]$. Examples of detectors used in gas chromatographs include the following: atomic emission detectors (AEDs) and flame iomization detector [13]. Flame photometric detectors, pulsed flame photometric detector (PFPD) and sulfur chemiluminescence detectors (SCDs) [14, 15]. FPDs, which are highly selective for phosphorus- and sulfur-containing compounds, can detect $20 \mathrm{ng} / \mathrm{m}^{3}$ of organo phosphorus compounds and $200 \mathrm{ng} / \mathrm{m}^{3}$ of organo sulfur compounds within $30 \mathrm{~s}$ [15-17].

In this paper the application of gas chromatography equipped with flame photometric detector has been used in addition factors affecting detection by GC/FPD have been investigated.The effect of experimental conditions such as gas flow rates, detector temperature and column temperature on the response of a flame photometric detector (FPD) operating in the sulphur mode have been studied.

\section{Experimental Work}

\subsection{Reagents and Materials}

Reagents required for standard solutions must be of high purity. Analytical grade chemical reagents were used for GC purposes and other preparation standard. All reagent and standard solutions should be stored in glass bottles unless otherwise stated. The used reagents and materials in all analytical methods are given in Table (2.1); it provides the chemical 
Military Technical College

Kobry El-Kobbah,

Cairo, Egypt

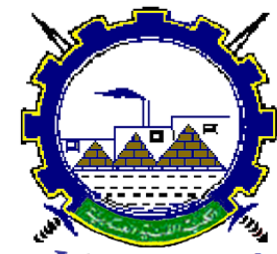

I.C.E.E.2016 $8^{\text {th }}$ International Conference

on

Chemical \& Environmental

Engineering

$19-21$ April 2016

structures, grades, and suppliers. All chemicals were used without more purification. The choice of the investigated chemicals is based on recent study, availability and economic aspects. CEES and analytical solvents were purchased from Sigma Aldrich.

Table (2. 1) Chemicals used in the experimental work

\begin{tabular}{||c|c|c|c|c||}
\hline No. & Solvent & Chemical formula & Grade & Supplier \\
\hline \hline 1 & Deionized water & $\mathrm{H}_{2} \mathrm{O}$ & HPLC & Fulka \\
\hline 2 & chloroform & $\mathrm{CHCl}_{3}$ & HPLC & Aldrich \\
\hline 3 & CEES & $\mathrm{C}_{4} \mathrm{H}_{9} \mathrm{SCl}$ & HPLC & Aldrich \\
\hline
\end{tabular}

\subsection{Preparation of Standards}

Stock Standard solution of CEES was prepared by accurately weighing about $0.3 \mathrm{~g}$ of CEES (without correction)[18] and then dissolve in $100 \mathrm{ml}$ chloroform solvent. Weighing was performed using calibrated digital analytical balance type SCALTEC SBA 31 (maximum 220 and $\pm 0.0001 \mathrm{gm}$ accuracy). Series of standards solutions of CEES have been prepared by diluting to a volume of $25-\mathrm{mL}$ volumetric flask. The prepared stock standard solutions transferred into TFE-fluorocarbon-sealed screw-cap vials. The prepared stock standard solutions stored at $4{ }^{\circ} \mathrm{C}$ and protect from light. Stock standard solutions frequently checked for degradation or evaporation. The prepared stock standard solutions must be replaced after 6 months or sooner if comparison with check standards indicates a problem.

\subsection{Instruments and Equipments}

The analysis was performed on Agilent 7890A GC coupled with Flame Photometric Detector. The main parts of the instrument are: The injector: Agilent technology. The column: HP-5MS ( $30 \mathrm{~m} \times 0.320 \mathrm{~mm} \times 0.25 \mu \mathrm{m})$, non-polar stationary phase. The detector: flame photometric detector (FPD), H9261. Auto Sampler: Agilent 7683B, 5.0- $\mu \mathrm{L}$ syringe. All system parameters can be automatically controlled through chemistation Rev. B. 03.02 software. The materials were weighed by A Heligenst SCALTEC, Germany analytical balance. Volumes taken for standard solution preparation was taken by Automatic pipette high performance micro pipette Vrobfiels, USA . The pipette was calibrated according to EV-ISO8655. The calibration passed the test. 
Military Technical College

Kobry El-Kobbah,

Cairo, Egypt

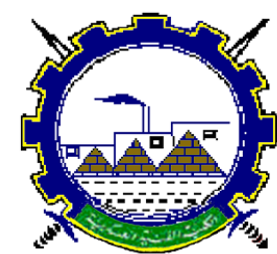

I.C.E.E.2016 $8^{\text {th }}$ International Conference

on

Chemical \& Environmental

Engineering

19 - 21 April 2016

\subsection{Operating Conditions.}

Operating condition has been taken as standard method described by Agilent technology for the analysis of sulfur and phosphorus compound with flame photometric detector on the Agilent 6890 Series Gas Chromatograph [19].the conditions were, carrier gas Ultra-pure Nitrogen $99.999 \%$, temperature, program: $60{ }^{\circ} \mathrm{C}$ for $1 \mathrm{~min}$ and then programmed at $20{ }^{\circ} \mathrm{C}$ $/ \mathrm{min}$ to $250{ }^{\circ} \mathrm{C}$, and held for $5 \mathrm{~min}$. The total analysis time was $15.5 \mathrm{~min}$. Inlet: Split less mode; injector temperature $250^{\circ} \mathrm{C}$ and injection volume: $1 \mu$ l. detector FPD phosphorous and sulfur mode, detector temperature $250{ }^{\circ} \mathrm{C}$. These conditions have been optimized for the determination of CEES. The detector response used for the optimization of GC/FPD condition through studying injector temperature, temperature program, carrier gas flow rate and air to fuel ratios.

\subsection{Study of GC Conditions}

CEES standards at different concentration were injected into GC-FPD to optimize the separation condition of GC parameters including injector temperature, temperature program, flow rate of $\mathrm{N}_{2}$ carrier gas and air to fuel ratio.

\subsubsection{Injector temperature}

Injector temperature was studied in the range from 150 to $250{ }^{\circ} \mathrm{C}$ by fixing the detector temperature at $250{ }^{\circ} \mathrm{C}$ and using temperature program as initial temperature at $60{ }^{\circ} \mathrm{C}$ (hold 1 min), final temperature at $250{ }^{\circ} \mathrm{C}$ (rate $20{ }^{\circ} \mathrm{C} / \mathrm{min}$, hold $7 \mathrm{~min}$ ). The detector response for CEES was then measured by injecting 4 ppm 5 ppm of CEES and tabulate the detector response against injector temperature

\subsubsection{Initial temperature program}

using the same standard solution prepared above the initial temperature program was varied in the range of $50-100{ }^{\circ} \mathrm{C}$ by fixing other conditions constant, injector temperature $250{ }^{\circ} \mathrm{C}$ without decomposition effect, the detector temperature $250{ }^{\circ} \mathrm{C}$ and oven final temperature at $250{ }^{\circ} \mathrm{C}$ (rate $20{ }^{\circ} \mathrm{C} / \mathrm{min}$, hold $7 \mathrm{~min}$ ). the change in retention time and detector response were then tabulated against initial temperature.

\subsubsection{Carrier gas flow rate (constant volume)}

The FPD response was also studied with the change in carrier gas flow rate (Nitrogen in this case) from 10 to 35 psi. The detector response was then measured tabulates the results. 
Military Technical College

Kobry El-Kobbah,

Cairo, Egypt

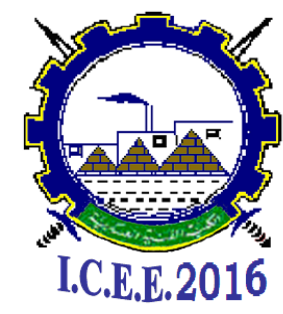

$8^{\text {th }}$ International Conference

on

Chemical \& Environmental

Engineering

$19-21$ April 2016

\subsubsection{Air to fuel ratio supplied (S-mode)}

In the analysis of sulfur compound with flame photometric detector S-mode the absolute gas flow rate is: $50 \mathrm{ml} / \mathrm{min}$ for hydrogen gas and $60 \mathrm{ml} / \mathrm{min}$ for air according to standard method [19]. This method has been also studied and the linear range, sensitivity, accuracy and precision have been determined. The effect of changing absolute and relative flow rates of gases supplied to the detector S-mode has been studied with the same other condition in the method. Standard solution of CEES has been prepared and measured as discussed before. The effect of relative flow rate air-to-hydrogen flow rates has been studied in the ratio range from 0.4 to 1.2 (volumetric ratio).

\section{Results and Discussions}

\subsection{GC/FPD S- mode Optimization}

The optimization of GC condition was adjusted for enhancing resolution and sensitivity of the analytes by studying the effect of varying flow rate of the carrier gas, setting temperature parameters and air to fuel ratio. Standard Agilent method was used for starting the analysis of the investigated analytes. Nitrogen was used as a carrier gas. Hydrogen and air (zero impurities) were used as fuel and oxidant gases for igniting flame in the FPD. The response variables used for the optimization were considered such as peak area, peak shape and retention time. Methods validation of these parameters were evaluated by determining retention time, linear range, sensitivity, accuracy, precision and detection limit

\subsubsection{Injector temperature}

Injector temperature was studied while fixing the detector temperature at $250{ }^{\circ} \mathrm{C}$ and using suitable temperature program. Initialtemperature was set at $60^{\circ} \mathrm{C}$ (hold $1 \mathrm{~min}$ ), final temperature at $250^{\circ} \mathrm{C}$ with increasing rate $20^{\circ} \mathrm{C} / \mathrm{min}$, hold $7 \mathrm{~min}$ ). Figure 1 shows the relation between injector temperature and detector response (peak area). The figure summarized that the highest peak area of all samples were obtained at $250{ }^{\circ} \mathrm{C}$, this could be attributed to the highest volatility of the samples introduced in the column.

\subsubsection{Temperature programming}

For the purpose of this optimization the initial temperature was varied in the range of $50-100$ ${ }^{\circ} \mathrm{C}$ while fixing the injector temperature $250{ }^{\circ} \mathrm{C}$ and the detector temperature at $250{ }^{\circ} \mathrm{C}$. The results show that as the initial temperature increasesthe retention time of analytes decreases. Figure 2 (a) Shows the relation between initial temperature program and retention time. From the figure, it was clear that as the initial temperature increases the retention time decrease this was due to fast elution of the analyte from the column. This parameter is very important in optimizing peak resolution. 
Military Technical College

Kobry El-Kobbah,

Cairo, Egypt

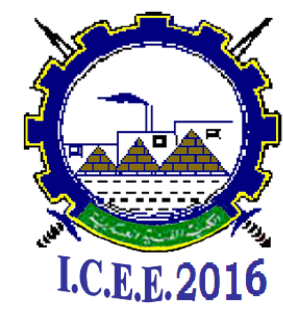

$8^{\text {th }}$ International Conference

on

Chemical \& Environmental

Engineering

$19-21$ April 2016

Figure 2 (b) Showed the relation between initial temperature program and detector response (peak area). At temperature between 50 to $70{ }^{\circ} \mathrm{C}$ the detector response (peak area) increases this may due to shape of the produced peak area shape in which at low temperature the peak was broad which gives more area count however at more higher temperature above $70^{\circ} \mathrm{C}$ the peak shape was observed to be sharp, which produced lower area count. Therefore, the optimum initial temperature was found at $70^{\circ} \mathrm{C}$ which was selected because of shortretention time and high peak area

\subsubsection{Carrier gas inlet pressure}

The FPD response was also found to be dependent on the carrier gas inletpressure (nitrogen in this case). Figure 3 showed the relation between the detector response and the carrier gas inlet pressure.

It was cleared that the FPD signal increases with increasing carrier gasflow-rates; this was to a certain value (25 psi) this may be due to the enhancing for a decrease in the flame temperature to be (cooled flame) in which at this region the emission from the species (HPO and $\left.\mathrm{S}_{2}\right)$ is favored. Above this certain value (25 psi) a decrease in the detector response was observed. It may due to highly lowering in the flame temperature. The suitable pressure was as in standard method at 25 psi. Carrier gases must be especially purified for use in the flame photometricdetector because not highly purified led to substantial narrowing of the linear dynamic range of the detector.

\subsubsection{Air to hydrogen ratio supplied to the detector (FPD-S mode)}

Effect of the ratio of air-to-hydrogen from 0.5-to-1.2 in detector FPD-S mode has been studied.Figure 4 shows the relation between the detector response and ratio (volumetric ratio). At ratio 0.5 and below the amount of oxygen exist was only 0.1 mole that cannot generate the flame so the devise gives flame out. The result also shows that by increasing the ratio $(0.6$, $0.7,0.8,0.9,1)$ the response increase this may be due to an increase in the ratio produce lowering in the amount of un reacted hydrogen in the flame, this was to certain value where the flame become in the region of cooled zone flame with suitable high temperature $\left(500{ }^{\circ} \mathrm{C}\right)$ [20] that cause complete excitation of the $\mathrm{S}_{2}$ active molecule present in the flame region.

\subsection{Analytical Performance of GC/FPD (S-mode)}

Method validation confirms that the performing method is suitable and reliablefor the analysis. All the parameters obtained from the analytical procedures werequantified by GCFPD S- mode using the optimum conditions. The analytical performanceconsists of retention time reproducibility $\left(t_{R}\right)$, linear range, sensitivity, correlation coefficient, limit of detection(LOD), limit of quantification and percentage relative standard deviation (\%RSD). 
Military Technical College

Kobry El-Kobbah,

Cairo, Egypt

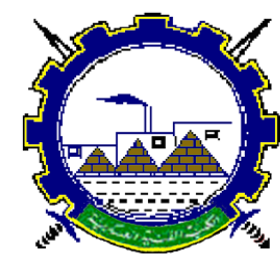

I.C.E.E.2016 $8^{\text {th }}$ International Conference

on

Chemical \& Environmental

Engineering

$19-21$ April 2016

\subsubsection{Calibration and Linear range}

The working solutions of different concentrations were prepared by appropriate dilution of the stock solution and then injection of $1 \mu 1$ of samples to GC-FPD-S mode. A calibration curve was plotted through a relation between detector response (area under the curve) and concentration of CEES as shown in Figure 5. The regression error analysis was made and the standard error of CEES was \pm 1.963 . The correlation coefficient of both CEES was 0.999 .

The linearity of CEES under the optimized condition described above was studied. The working solutions of different concentrations were prepared by appropriate dilution of the stock solution and then injection of $1 \mu 1$ of samples to the device, a relation between detector response (area under the curve) and concentration was plotted as shown in Figure 6 . The plot shows the linearity of the detector responsewith CEES in the range of 0.15 to $10 \mathrm{ng} / \mathrm{ml}$ with $\mathrm{R}^{2}$ value higher than 0.999 and standard error was \pm 0.0646 .The results show that the linear range was very small so in the sulfur mode of operation, the FPD generally exhibits a response that is a nonlinear and there was power law function of mass flow rate of $\mathrm{S}$ atoms in the flame.

The non linearity is due tothe emission mechanism of the sulphur groups, $\mathrm{S}_{2}$ or $\mathrm{SO}_{2}$. With both groups, anexponential increase in the number of emitting groups occurs, according to the schemes given below. By three-body recombination with substance M,which is not a hydrogen atom, an excited state is formed[20]

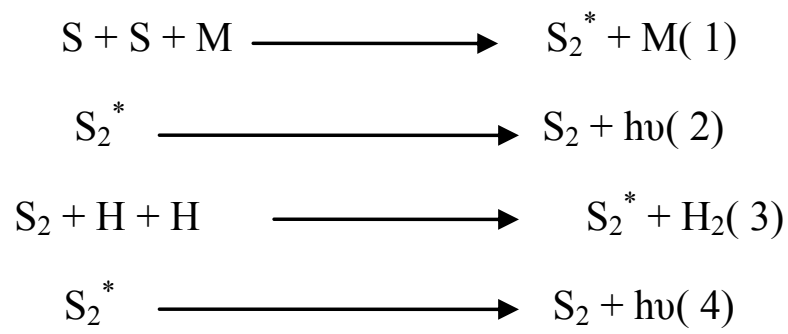

Therefore, sulphur sensitivity requires first a determination of the power law of response. In the case of the $\mathrm{S}_{2}$ emission, the light intensity is generally a nonlinear function of S-atom flow into the flame, and most often is found to vary as the approximate square of the S-atom flow $[21,22]$.

\subsubsection{Power low of sulfur response}

Figure 7 show the relation between mass of sulphur atom flow rate and the detector response. The detector response was plotted versus on $\log / \log$ graph scale for a series of standard solutions and determine the slope of a straight line as shown in Figure 7. This slope determined is used to determine the sulfur power law parameter (n). From the figure the value of $\mathrm{n}=1.891$ which lies on the typical range values. 
Military Technical College

Kobry El-Kobbah,

Cairo, Egypt

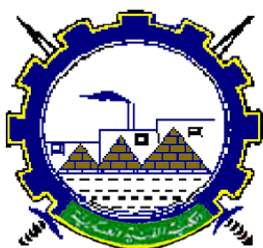

I.C.E.E.2016 $8^{\text {th }}$ International Conference

on

Chemical \& Environmental

Engineering

$19-21$ April 2016

\subsubsection{Sensitivity measurements}

By injecting a known concentration of $2.5 \mathrm{ppm}$ in a test substance into the flowing carrier gas stream and permit the peak to be detected by the detector (change in detector response with concentration), then from calculating the power law of sulphur response the sensitivity of the detector can be measured. The sensitivity was $17.5 \mathrm{~A} /(\mathrm{gS} / \mathrm{s})^{2}$ for CEES where the typical value was $(2-20) \mathrm{A} /(\mathrm{gS} / \mathrm{s})^{2}$.

\subsubsection{Limit of Detection (LOD)}

The limit of detection (LOD) of FPD-S mode under the optimized condition was done to determine the lowest concentration of CEES that could be detected by the GC-FPD-S mode. From the Figure 8 it can be seen that the lowest concentration of CEES which can be detected at $(\mathrm{S} / \mathrm{N}=2)$ was $0.15 \mathrm{ng} / \mathrm{ml}$.

\subsection{Optimized operating conditions}

After studying the parameters that affect the detector response, the suitable operating parameters can be established as shown in Table 3.1. These parameters will be used for further validation of the method and also measuring the performance of the GC/FPD.

Table (3. 1) Optimum GC/FPD operating conditions (S-mode)

\begin{tabular}{|c|c|}
\hline Parameter & Condition \\
\hline Separation Column & $\begin{array}{l}\text { HP-5 (5\% cross linked Methyl Phenyl Silicone) } 25 \mathrm{~m} \mathrm{x} 0.2 \mathrm{~mm} \text { i.d. } \\
\text { x } 0.52 \mu \mathrm{m} \text { film thickness }\end{array}$ \\
\hline Carrier gas pressure & $\mathrm{N}_{2}$ at $2 \mathrm{ml} / \mathrm{min}, 25 \mathrm{psi}$ \\
\hline Fuel gas(Hydrogen) & $50 \mathrm{ml} / \mathrm{min}$ \\
\hline Oxidant gas(Air) & $60 \mathrm{ml} / \mathrm{min}$ \\
\hline Make up gas $\left(\mathrm{N}_{2}\right)$ & $60 \mathrm{ml} / \mathrm{min}$ \\
\hline Mode & S-mode \\
\hline Injection volume & $1 \mu \mathrm{L}$ \\
\hline Injection mode & splitless mode \\
\hline Injection temperature & $250{ }^{\circ} \mathrm{C}$ \\
\hline Detector temperature & $250^{\circ} \mathrm{C}$ \\
\hline Temperature program & $\begin{array}{c}70{ }^{\circ} \mathrm{C}(1 \mathrm{~min}), \text { rate } 20{ }^{\circ} \mathrm{C} / \mathrm{min} \text { to } 250{ }^{\circ} \mathrm{C} \\
\text { maintained for } 7 \mathrm{~min}\end{array}$ \\
\hline
\end{tabular}

\section{4 conclusion}

Analysis of CEES showed the validity of the optimized method used, which allowed the determination of CEES. The method is simple, precise, rapid and reproducible and has low level of linearity. The factors affecting detector response are very important for a chemist to be aware specially air to hydrogen ratio and carrier gas inlet pressure. The FPD response is reported as being affected by the Oxygen: hydrogen ratio in the detector. 
Military Technical College

Kobry El-Kobbah,

Cairo, Egypt

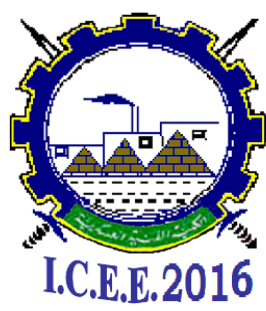

$8^{\text {th }}$ International Conference

on

Chemical \& Environmental

Engineering

$19-21$ April 2016

\section{References}

[1] Stout, S.C., S.C. Larsen, and V.H. Grassian, Adsorption, desorption and thermal oxidation of 2-CEES on nanocrystalline zeolites. Microporous and mesoporous materials, 2007. 100(1): p. 77-86.

[2] Quimby, B. and M.J. Szwlewski, Detection and Measurement of Chemical Warfare Agents. Agilent Technologies, publication.

[3] Fonger, G.C., Hazardous substances data bank (HSDB) as a source of environmental fate information on chemicals. Toxicology, 1995. 103(2): p. 137-145.

[4] Popiel, S. and M. Sankowska, Determination of chemical warfare agents and related compounds in environmental samples by solid-phase microextraction with gas chromatography. Journal of Chromatography A, 2011. 1218(47): p. 8457-8479.

[5] Samadi, S., H. Sereshti, and Y. Assadi, Ultra-preconcentration and determination of thirteen organophosphorus pesticides in water samples using solid-phase extraction followed by dispersive liquid-liquid microextraction and gas chromatography with flame photometric detection. Journal of Chromatography A, 2012. 1219: p. 61-65.

[6] Zhang, Q., et al., Analysis of chlorpyrifos and TCP residues in agricultural soil and apples by HPLC. Journal of Food, Agriculture \& Environment, 2011. 9(1): p. 659-662.

[7] Wils, E., A. Hulst, and A. De Jong, Determination of mustard gas and related vesicants in rubber and paint by gas chromatography-mass spectrometry. Journal of Chromatography A, 1992. 625(2): p. 382-386.

[8] Creasy, W.R., et al., Identification of chemical-weapons-related compounds in decontamination solutions and other matrices by multiple chromatographic techniques. Journal of Chromatography A, 1997. 774(1): p. 253-263.

[9] van der Schans, G.P., et al., Immunochemical detection of sulfur mustard adducts with keratins in the stratum corneum of human skin. Chemical research in toxicology, 2002. 15(1): p. 21-25.

[10] Zou, M.C.a.Y., A Rapid Method for Trace Analysis ofOrganophosphorus Pesticides inDrinking Water. Agilent Technologies, publication, 2008

[11] Thomas, O. and C. Burgess, UV-visible Spectrophotometry of Water and Wastewater. Vol. 27. 2007: Elsevier.

[12] Hill, H.H. and S.J. Martin, Conventional analytical methods for chemical warfare agents. Pure and applied chemistry, 2002. 74(12): p. 2281-2291.

[13] D'Agostino, P.A. and C. Chenier, Analysis of Chemical Warfare Agents: General Overview, LC-MS Review, In-House LC-ESI-MS Methods and Open Literature Bibliography. 2006, DTIC Document.

[14] Edwin W.J. Hooijschuura, C.E.K., Udo A.Th. Brinkmana, Application of microcolumn liquid chromatography and capillaryelectrophoresis with flame photometric detection for the screeningof degradation products of chemical warfare agents in water andsoil. Journal of Chromatography A, 2001: p. 187-199.

[15] Barwick, V.J., Sources of uncertainty in gas chromatography and high-performance liquid chromatography. Journal of Chromatography A, 1999. 849(1): p. 13-33. 
Military Technical College Kobry El-Kobbah, Cairo, Egypt

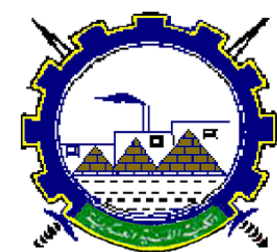

I.C.E.E.2016 $8^{\text {th }}$ International Conference

on

Chemical \& Environmental

Engineering

19-21 April 2016

[16] Frishman, G. and A. Amirav, Fast GC- PFPD system for field analysis of chemical warfare agents. Field Analytical Chemistry \& Technology, 2000. 4(4): p. 170-194.

[17] Agilent, Analysis of Organophosphorus Pesticides with Agilent 7820 Gas Chromatograph/ Flame Photometric Detector. 2011.

[18] EPA, ASSAY OF CHEMICAL AGENTS IN SOLID AND AQUEOUS SAMPLES BY GAS CHROMATOGRAPHY/FLAME PHOTOMETRIC DETECTION (GC/FPD). EPA publications, 2007.

[19] Wilson, W.H. and M.S. Klee, Analysis of sulfur and phosphorus compounds with a flame photometric detector on the Agilent 6890 Series Gas Chromatograph. Innovating the HP way Manual, 1997: p. 1-4.

[20] éSevécâik, J., Detectors in gas chromatography. Vol. 4. 1976: Elsevier Scientific Pub. Co.(Amsterdam and New York).

[21] Bidari, A., et al., Sample preparation method for the analysis of some organophosphorus pesticides residues in tomato by ultrasound-assisted solvent extraction followed by dispersive liquid-liquid microextraction. Food Chemistry, 2011. 126(4): p. 1840-1844.

[22] Zhang, J., et al., Optimization for speed and sensitivity in capillary high performance liquid chromatography. The importance of column diameter in online monitoring of serotonin by microdialysis. Journal of Chromatography A, 2012. 1251: p. 54-62. 
Military Technical College Kobry El-Kobbah,

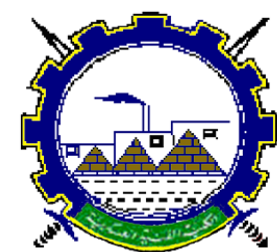

I.C.E.E.2016 $8^{\text {th }}$ International Conference on

Chemical \& Environmental Engineering

$19-21$ April 2016

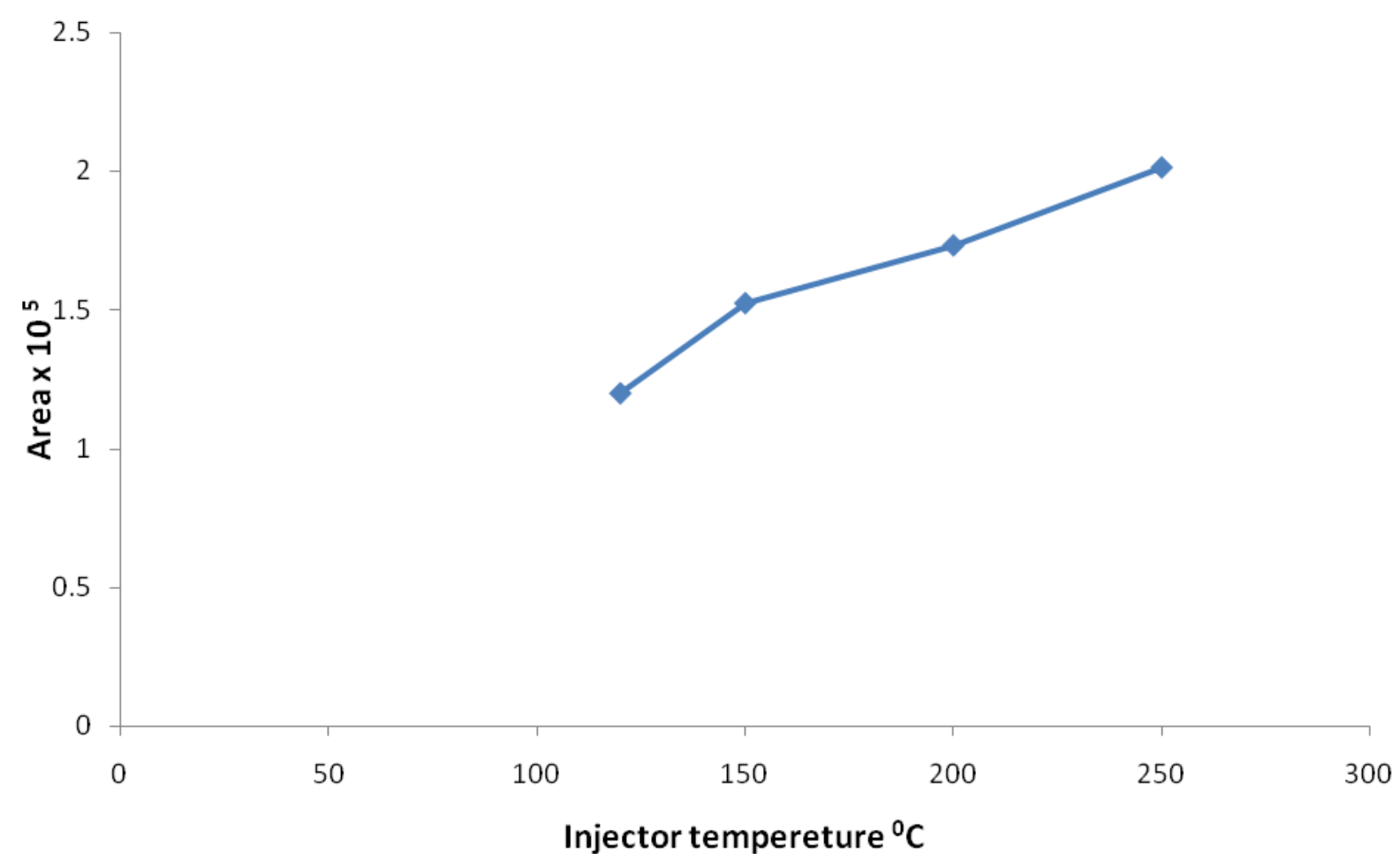

Fig. 1 Effect of injector temperature on peak area using splitless mode injection volume $(1 \mu \mathrm{l})$ detector temperature $250^{\circ} \mathrm{C}$ 
Military Technical College

Kobry El-Kobbah,

Cairo, Egypt

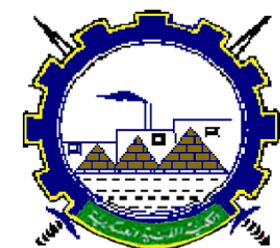

I.C.E.E.2016 $8^{\text {th }}$ International Conference

on

Chemical \& Environmental

Engineering

19 - 21 April 2016

(a)

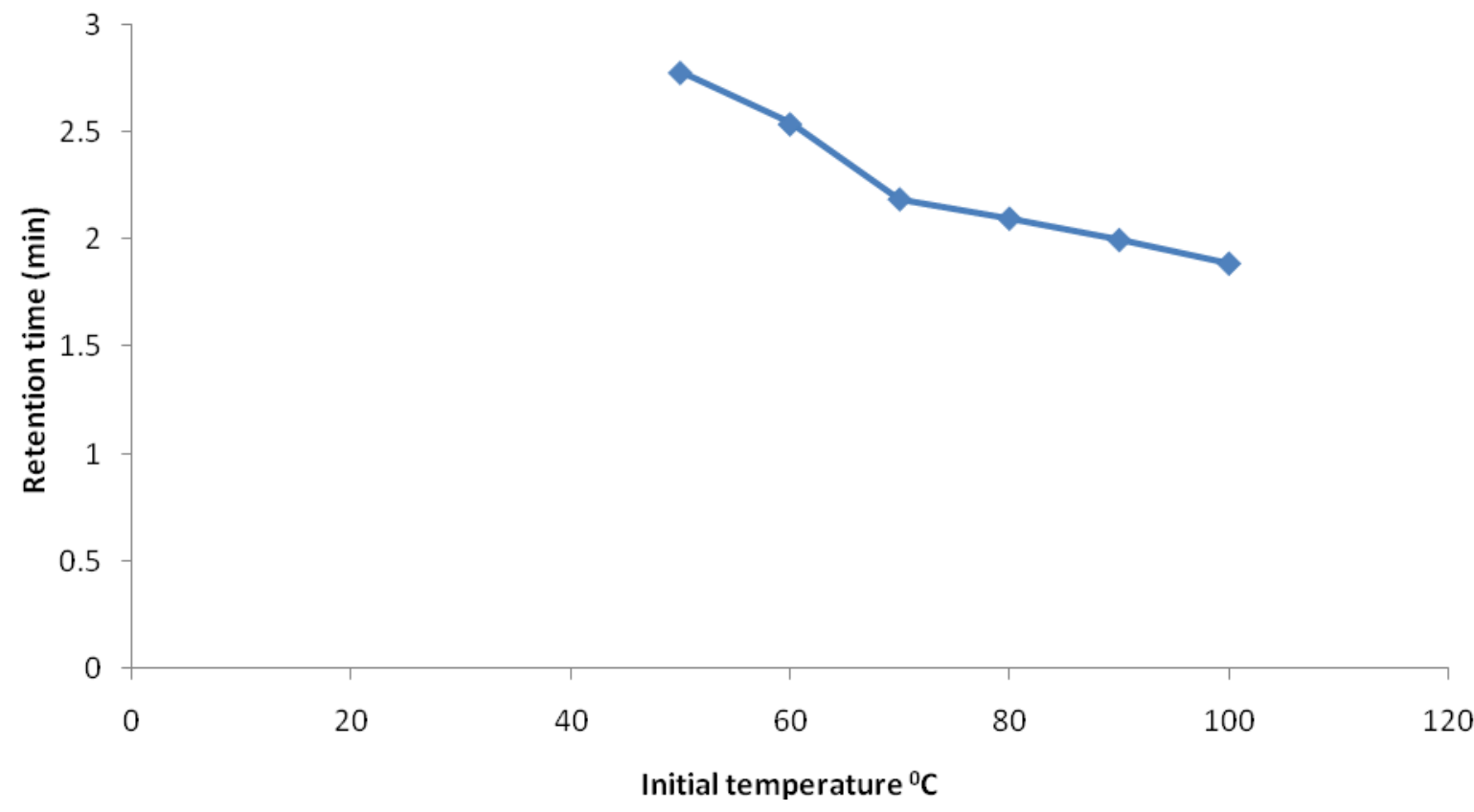

(b)

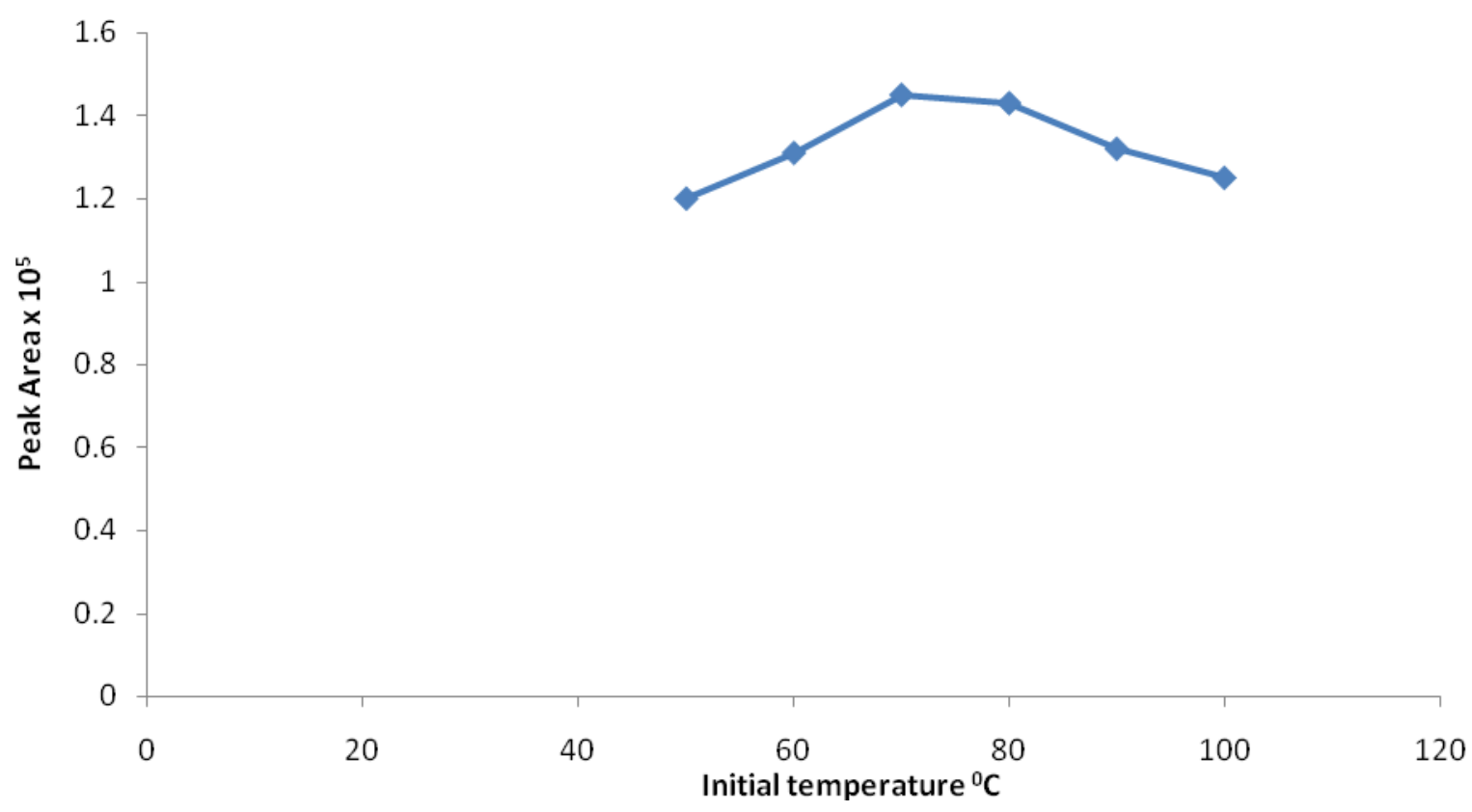

Fig.2 Effect of initial temperature program on (a) retention time and (b) peak area using splitless mode injection volume $(1 \mu \mathrm{l})$ detector temperature $250{ }^{\circ} \mathrm{C}$ 
Military Technical College Kobry El-Kobbah,

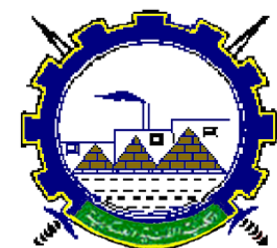

I.C.E.E.2016 $8^{\text {th }}$ International Conference

on

Chemical \& Environmental

Engineering

$19-21$ April 2016

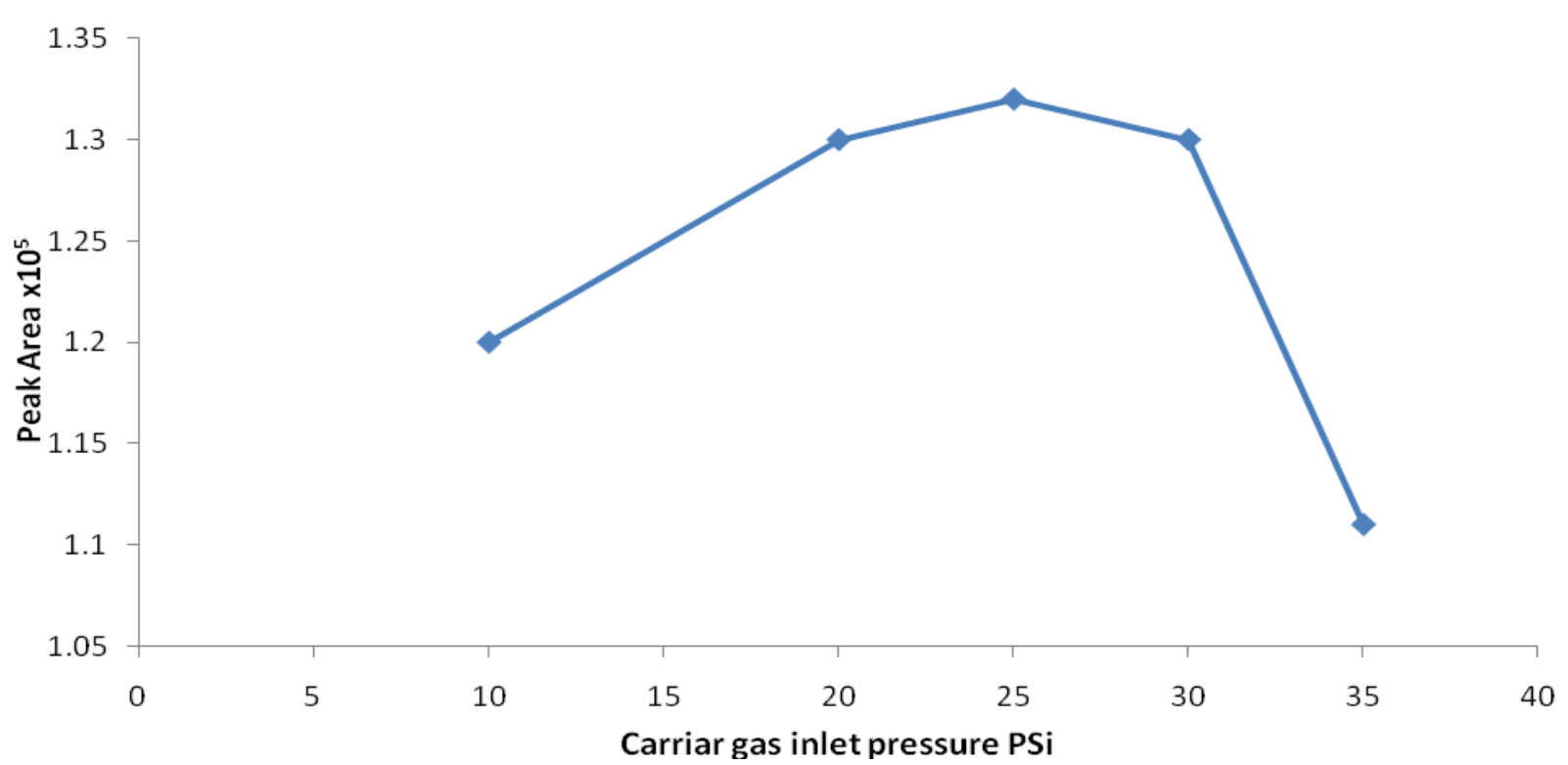

Fig.3 Effect of carrier gas inlet pressure splitless mode injection volume $(1 \mu \mathrm{l})$ detector temperature $250{ }^{\circ} \mathrm{C}$

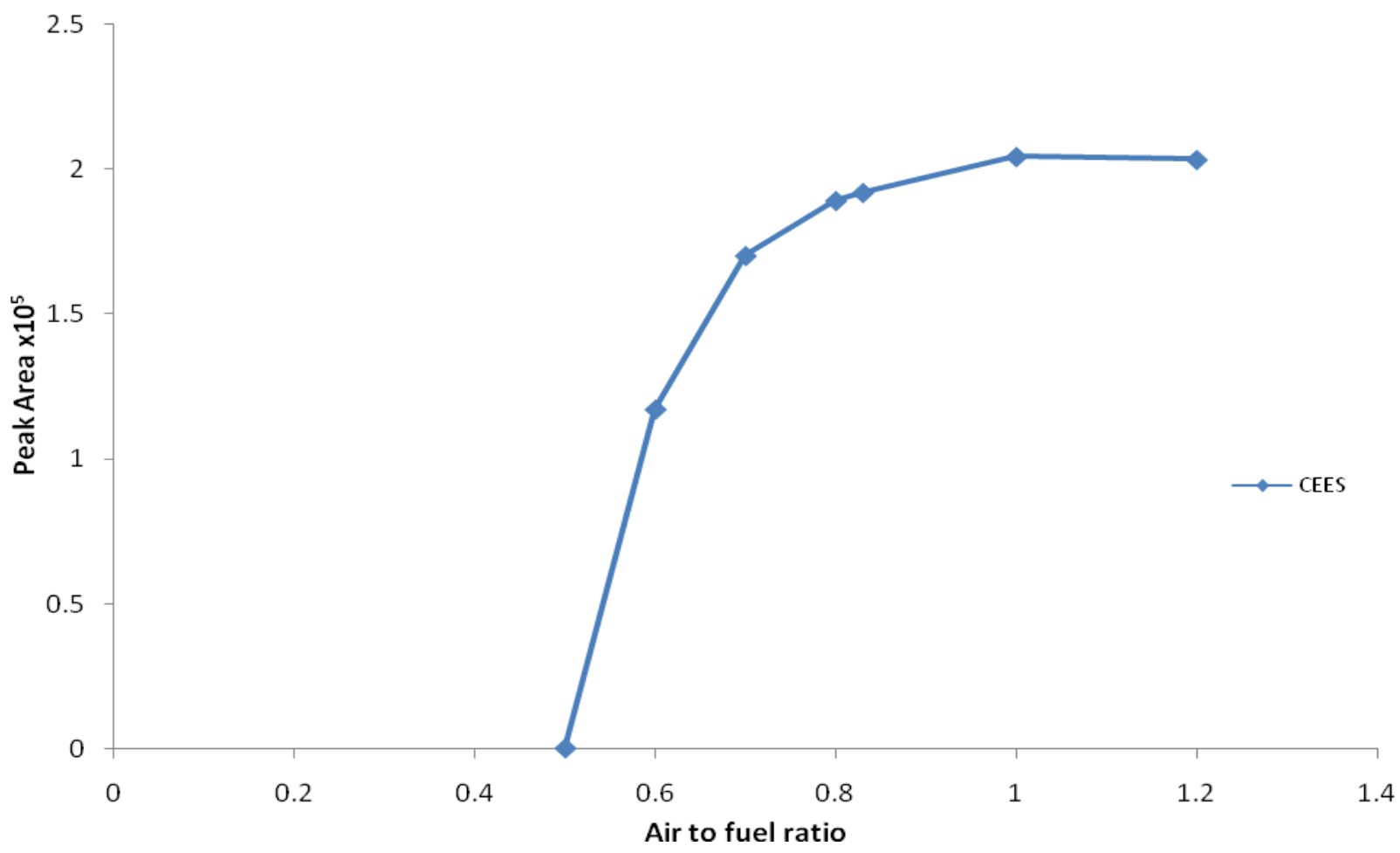

Fig.4 Effect of air to hydrogen ratio splitless mode injection volume $(1 \mu \mathrm{l})$ detector temperature $250{ }^{\circ} \mathrm{C}$ 
Military Technical College Kobry El-Kobbah,

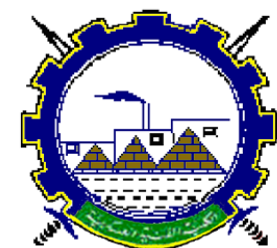

I.C.E.E.2016 $8^{\text {th }}$ International Conference

on

Chemical \& Environmental

Engineering

$19-21$ April 2016

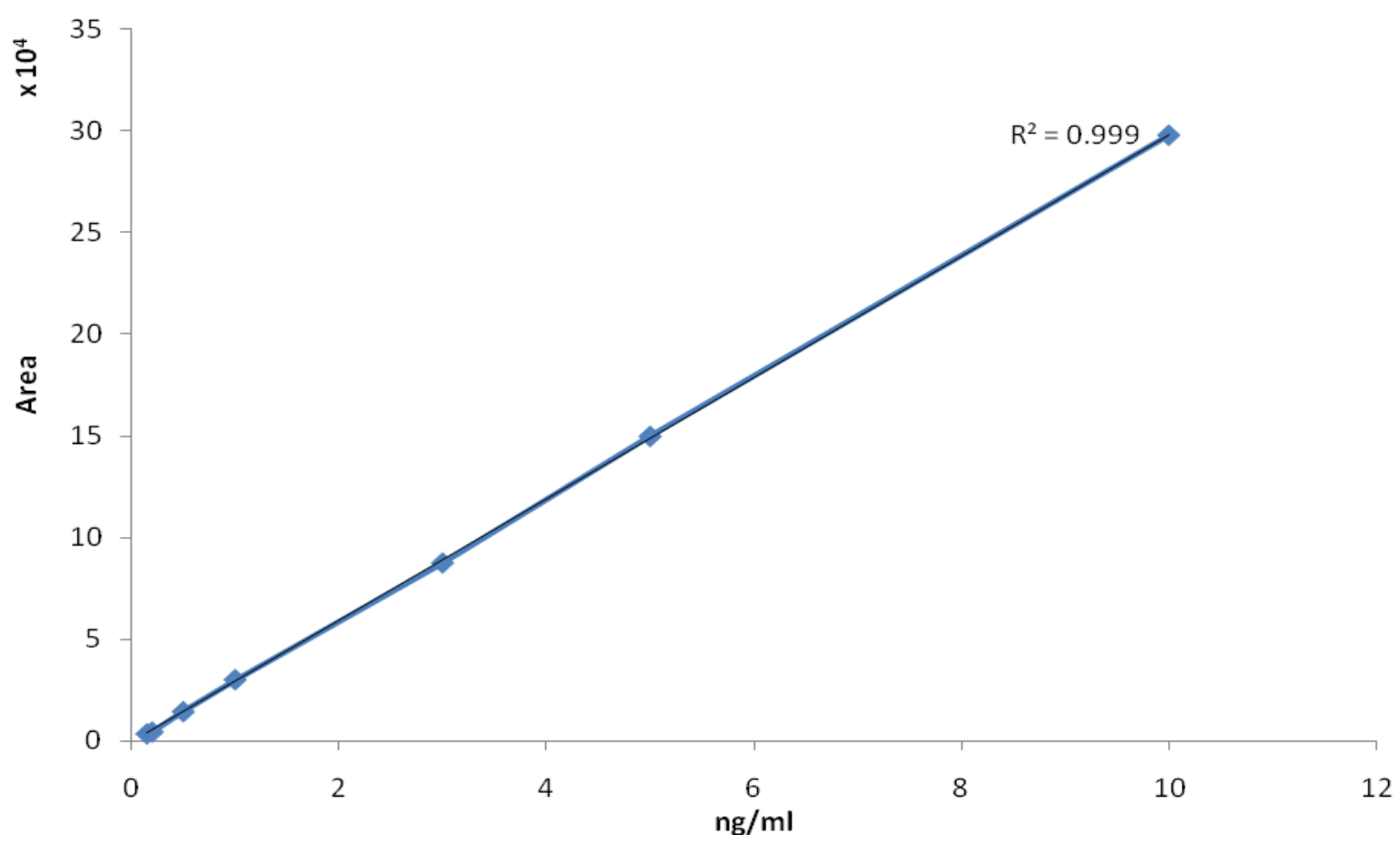

Fig. 5 Calibration curve of CEES $1 \mu \mathrm{l}$ injection in GC/FPD S-mode

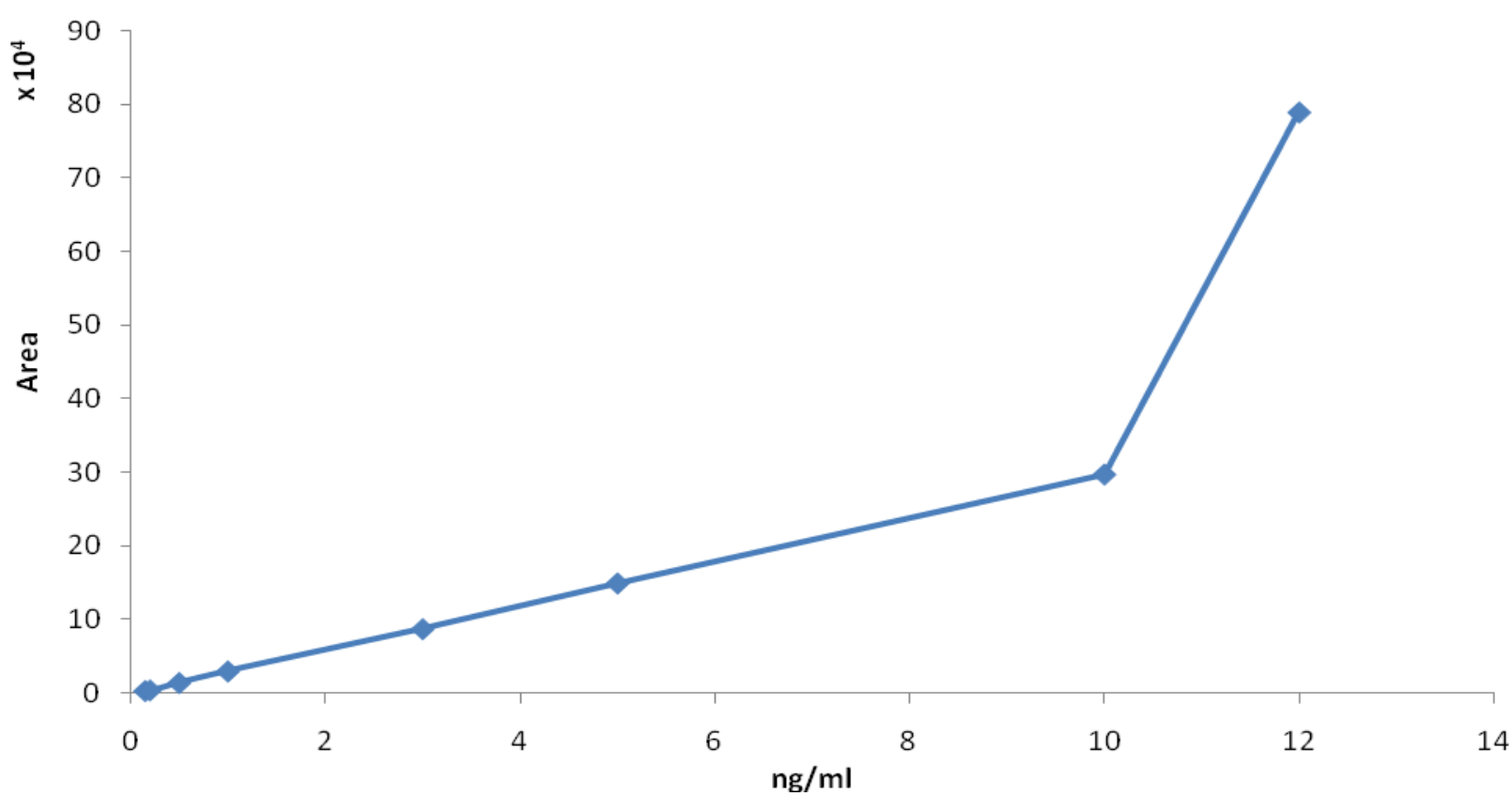

Fig. 6 Dynamic range of GC/FPD S-mode for CEES $1 \mu \mathrm{l}$ injection 
Military Technical College Kobry El-Kobbah, Cairo, Egypt

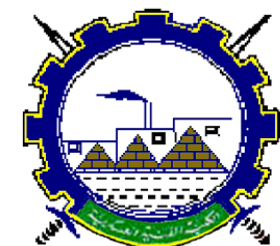

I.C.E.E.2016 $8^{\text {th }}$ International Conference

on

Chemical \& Environmental

Engineering

$19-21$ April 2016

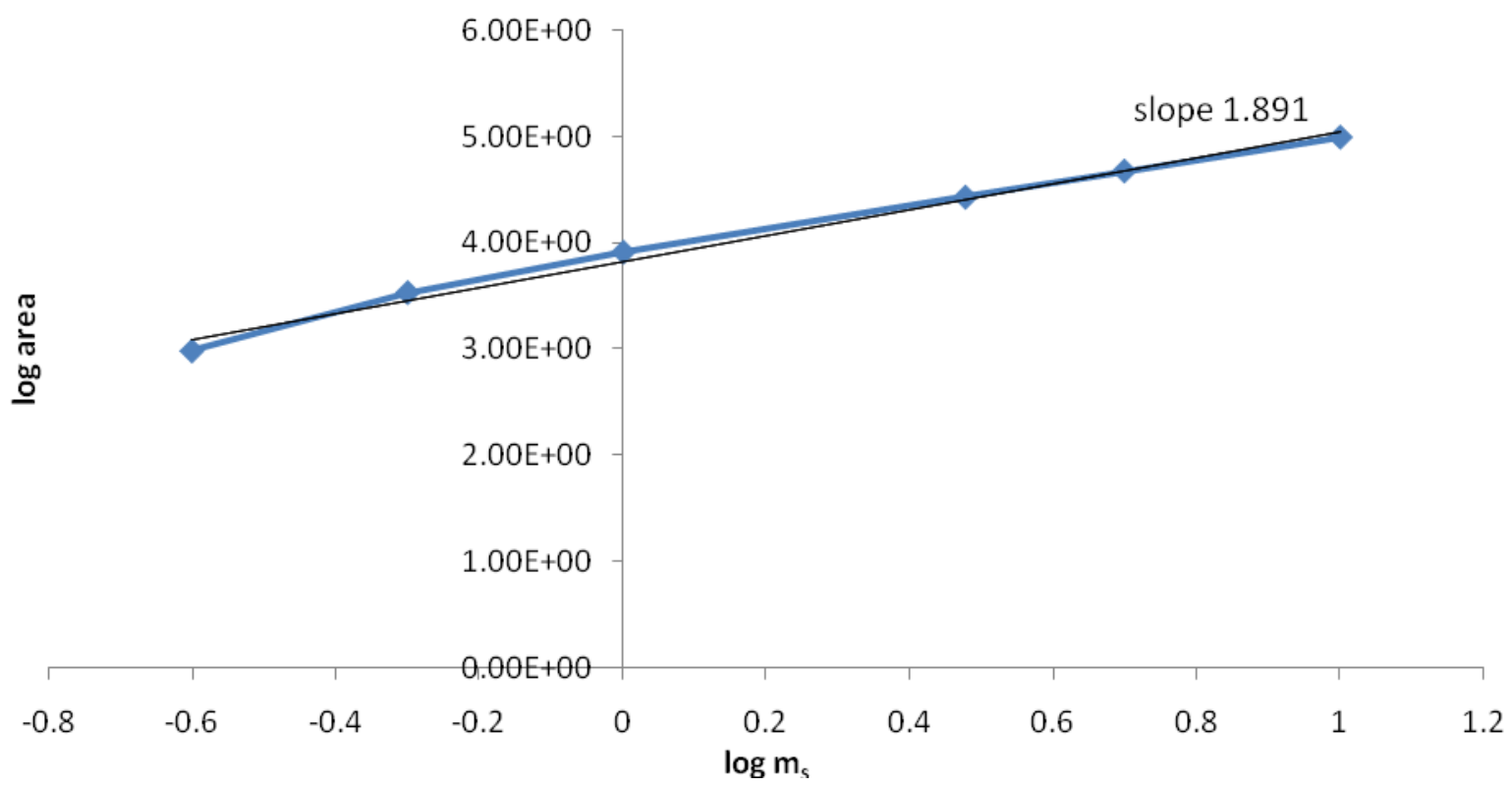

Fig. 7 Power law of sulphur response (S-mode) splitless mode injection volume (1 $\mu \mathrm{l})$ detector temperature $250{ }^{\circ} \mathrm{C}$

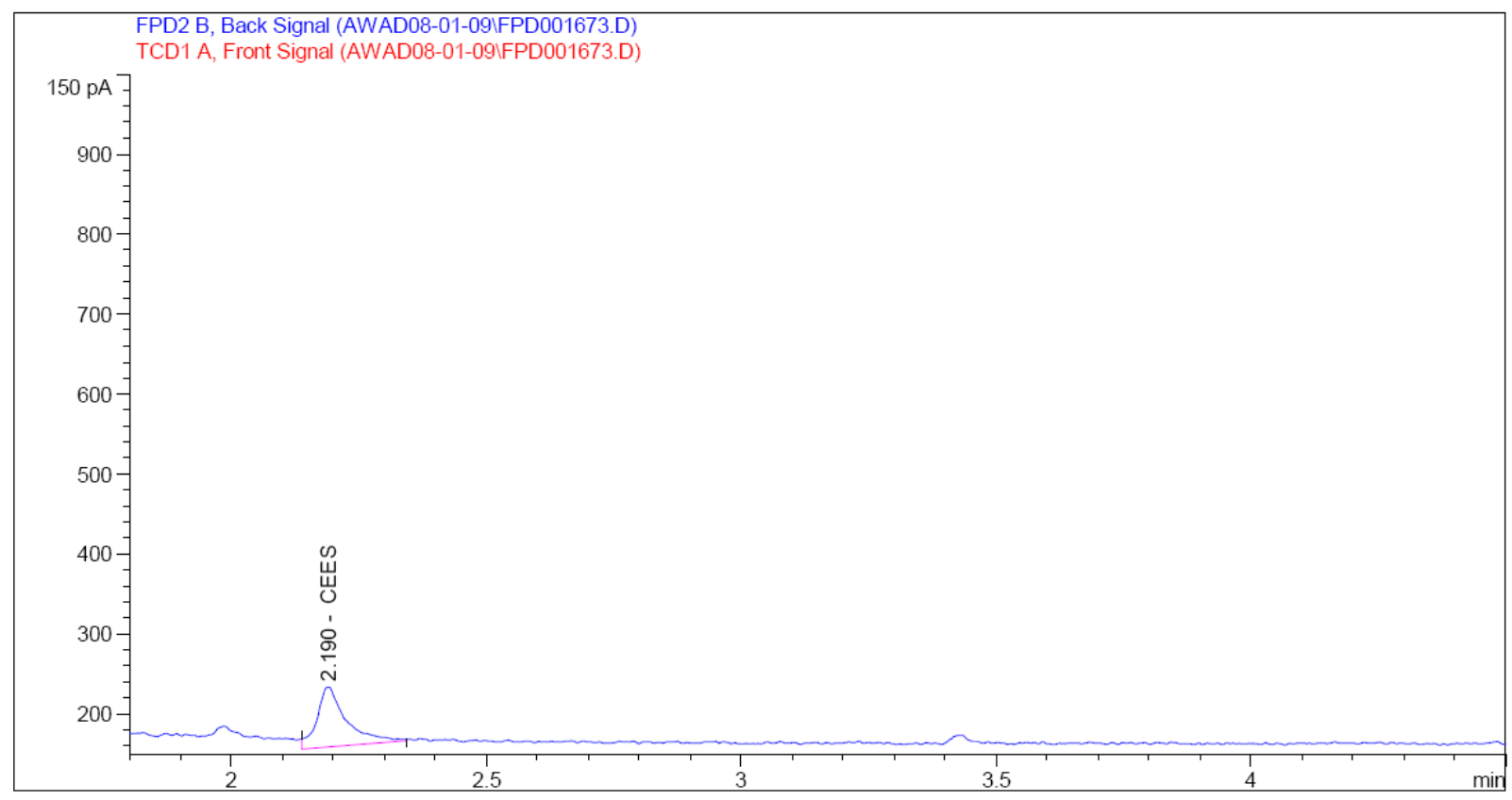

Fig. 8 Chromatogram of 0.15ng CEES LOD(S-mode) ratio, splitless mode, injection volume $(1 \mu \mathrm{l})$ and detector temperature $250^{\circ} \mathrm{C}$ 